\title{
Whole animal copper flux assessed by positron emission tomography in the Long-Evans cinnamon rat - a feasibility study
}

\author{
Karl-Dimiter Bissig ${ }^{1}$, Michael Honer ${ }^{2}$, Kurt Zimmermann ${ }^{2}$, Karl H. Summer ${ }^{3}$ \& \\ Marc Solioz ${ }^{1, *}$ \\ ${ }^{1}$ Department of Clinical Pharmacology, University of Berne, 3010 Berne, Switzerland; ${ }^{2}$ Center for Radio- \\ pharmaceutical Science, Paul Scherrer Institute, 5232 Villigen, Switzerland; ${ }^{3}$ Institute of Toxicology, GSF- \\ National Research Center for Environment and Health, 85764 Neuherberg, Germany; Current address: Mare \\ Solioz: Department of Clinical Pharmacology, University of Berne, Murtenstrasse 35, CH-3010 Berne, \\ Switzerland, *Author for correspondence (Tel.: +41-31-632-3268; Fax: +41-31-632 4997; E-mail: \\ marc.solioz@ikp.unibe.ch)
}

Received 23 July 2004; Accepted 4 August 2004; Published online December 2004

Key words: copper homeostasis, positron emission, tomography, Long-Evans cinnamon rat, Wilson disease, secretion, bile

\begin{abstract}
Copper is an essential trace element. However, excess copper can lead to oxidation of biomolecules and cell damage and copper levels must be carefully controlled. While copper homeostasis has been studied extensively at the cellular level, short-term body copper fluxes are poorly understood. Here, we assessed for the first time the feasibility of measuring whole body copper flux by positron emission tomography, using ${ }^{64} \mathrm{Cu}$. A comparative approach comparing the Long-Evans cinnamon (LEC) rat to the wild type was chosen. LEC rats are an accepted model for Wilson disease, an inherited disorder of copper excretion in humans. In LEC rats as well as in Wilson patients, the copper transporting ATPase, ATP7B, is defective. This ATPase is primarily expressed in the liver and serves in copper secretion via the bile. Dysfunction of ATP7B leads to accumulation of copper in the liver. A control and an LEC rat were transgastrically injected with $10 \mu \mathrm{g}$ of ${ }^{64} \mathrm{Cu}$ and the copper flux followed for three hours by whole animal PET and concomitant collection of bile, as well as the analysis of tissue following tomography. As seen by PET, the administered copper was largely trapped in the stomach and the proximal intestine, and without a significant difference between control and LEC rat. Due to an insufficient dynamic range of the PET technology, copper which was systemically absorbed and primarily transported to the liver could only be followed by sampling and by $\beta$-counting. Biliary copper excretion ensued after $15 \mathrm{~min}$ in the control rat, but was absent in the LEC rat. Biliary excretion reached saturation one hour after copper administration. The trapping of orally administered copper in the gastrointestinal tract may be an important mechanism to prevent copper toxicity under conditions of a sudden, excessive copper load, which cannot be alleviated by increased biliary secretion. This trapping does however limit the utility of PET to measure whole animal copper flux.
\end{abstract}

\section{Introduction}

Copper is an essential trace element. In living organisms, it serves as a cofactor for many enzymes due to its biologically suitable redox potential. However, copper excess can lead to random oxidation of biomolecules and thus causes toxic effects. Cellular copper level is therefore tightly controlled in all organisms. Recent work on the mechanism of copper homeostasis has given great insight into the mechanism of copper homeostasis at the cellular level. Key elements of copper flux in 
mammalian cells are two ATPases for copper transport into the trans-Golgi network and secretion into the bile, respectively, a plasma membrane copper transporter, and a number of copper chaperones which serve in the delivery of copper to specific cuproenzymes (see Andrews 2002; Luk et al. 2003; Lutsenko et al. 2003; Mercer et al. 2003; Thiele 2003; Prohaska \& Gybina 2004 for recent reviews).

In contrast to the detailed understanding of copper transport at the cellular level, very little is known about the short-term dynamics of copper fluxes at the level of the whole organism. Positron emission tomography (PET) offers a new tool to look at the distribution of ${ }^{64} \mathrm{Cu}$ in real-time in a living animal. The feasibility of using this technique was assessed here by following the fate of orally administered ${ }^{64} \mathrm{Cu}$ in rats over a period of $3 \mathrm{~h}$. For greater study-depth, normal and LongEvans Cinnamon (LEC) rats were compared. The LEC rat is an accepted animal model of human Wilson disease, which leads to copper accumulation, primarily in the liver, due to impaired copper excretion via the bile. Molecular studies have revealed that in both, LEC rats and Wilson patients, the copper transporting P-type ATPase, ATP7B, is defective (Petrukhin et al. 1993; Tanzi et al. 1993; Wu et al. 1994; Shah et al. 1997; Forbes \& Cox 1998; Ferenci et al. 2003). The ATPase belongs to the highly conserved family of CPx-type ATPases which translocate toxic as well as essential heavy metal ions across biological membranes (Lutsenko \& Kaplan 1995; Solioz \& Vulpe 1996).

When the radioisotope ${ }^{64} \mathrm{Cu}$ decays, a positron is emitted, which can be detected by PET. This technique has recently advanced to a state allowing the imaging of small animals with high resolution. In the present study, we applied PET to assess whole body fluxes of ${ }^{64} \mathrm{Cu}$ in a control and LEC rat. The study showed the feasibility of imaging ${ }^{64} \mathrm{Cu}$ in whole rats. However, the limited dynamic range of PET proved to be a major limitation. It was found that a bolus of orally administered copper was poorly resorbed. At the same time, biliary copper secretion was readily saturated. This suggests a mechanism for preventing copper toxicity by limiting intestinal absorption under a high copper load. This could explain the high copper tolerance of rats.

\section{Materials and methods}

\section{Animals}

The female LEC rat was obtained from Charles River, Japan, and the control female Wistar rat from Deutsche Versuchstierfarm, Tuttlingen, Germany. Rats were kept under a 14-h light and 10-h dark cycle and on a standard diet with $15 \mathrm{ppm}$ of copper (Provimi-Kliba AG, Kaiseraugst, Switzerland), along with tap water ad libitum. Prior to experiments, rats were starved for $12 \mathrm{~h}$.

\section{Animal experiments}

Animal experiments were performed under pentobarbital anesthesia $(50 \mathrm{mg} / \mathrm{kg}$, intraperitoneally). Right after animals had been anaesthetized, an abdominal incision was made in order to access the abdominal cavity. Bile flow was measured by cannulation of the bile duct with a polyethylene tube (PP-10, Laubscher AG, Hölstein, Switzerland) and external drainage and fractionation with a fraction collector. Ten $\mu \mathrm{g}$ $\mathrm{Cu}^{2+}$ (applied as a $\mathrm{CuSO}_{4}$ solution) with a specific $\gamma$-activity of $17.3 \mathrm{MBq} / \mu \mathrm{g}$ copper $\left(15.13 \mathrm{MBq}\right.$ of ${ }^{64} \mathrm{Cu}$ and $2.19 \mathrm{MBq}$ of ${ }^{67} \mathrm{Cu}$ ) was introduced into the stomach by transgastric injection. Immediately after injection, the abdominal incision was adapted and the PET analysis was started. At the end of experiments (180 min after start of PET analysis) the animals were exsanguinated. Liver, brain and spleen were harvested for weighing and $\beta$-counting. All animal experiments were performed in compliance with Swiss laws and regulations and had been approved by a State Committee on Ethics in Animal Experimentation.

\section{Production of radioactive copper}

${ }^{64,67} \mathrm{Cu}$ was produced by irradiating ${ }^{\text {nat }} \mathrm{Zn}$-target with protons at the $72 \mathrm{MeV}$ accelerator and following separation from the target material as described (Schwarzbach et al. 1995). For ${ }^{64} \mathrm{Cu}$ production the proton irradiation schedule was reduced to maximally $20 \mathrm{~h}$ and the $\mathrm{Zn}$-target was processed $12 \mathrm{~h}$ post end of bombardment (EOB). At this time the ratio of ${ }^{64} \mathrm{Cu} /{ }^{67} \mathrm{Cu}$ was $20 / 1$. 


\section{PET-analysis}

PET experiments were performed with the 16module variant of the quad-HIDAC tomograph (Oxford Positron Systems, Weston-on-the-Green, UK). The camera had four detector banks each comprising four HIDAC (high density avalanche chamber) modules. Each module consists of a multi-wire proportional chamber between lead layers containing a matrix of holes of $0.4 \mathrm{~mm}$ in diameter and $0.5 \mathrm{~mm}$ pitch. The field of view is $280 \mathrm{~mm}$ axially and $170 \mathrm{~mm}$ in diameter allowing the acquisition of whole body images in a single bed position. Anesthetized animals were fixed with adhesive tape and positioned in the camera such that the whole body was placed symmetrically in the center of the field of view. Body temperature was controlled by a rectal probe and kept at $37.3{ }^{\circ} \mathrm{C}$ by a thermocoupler and a heated air stream. Acquisition of PET data was initiated right after application of the radiotracer and lasted for $3 \mathrm{~h}$. PET data were acquired in list-mode and reconstructed using the OPL-EM algorithm (Reader et al. 1998) with a bin size of $0.5 \mathrm{~mm}$, a matrix size of $200 \times 200 \times 500$, and resolution recovery with width $1.3 \mathrm{~mm}$. Reconstruction did not include scatter, random, attenuation and decay correction. Seven time frames were reconstructed: $0-15,15-30 \quad 30-45 \quad 45-60 \quad 60-90$ 90-120 120-180 min. The volumetric image files of the first and last time frame were represented in three dimensions using the software VGStudio Max 1.1 (Volume Graphics GmbH, Heidelberg, Germany).

\section{Native blue gel electrophoresis}

Native blue gel electrophoresis on $6-16 \%$ linear polyacrylamide gradients was conducted and the migration position of serum proteins identified as described (Schagger \& von Jagow 1991; Muratsubaki et al. 2002). Gels were dried and radioactivity was measured on a PhosphoImager (Storm 840; Molecular Dynamics, Sunnyvale, USA).

\section{Results}

The female LEC rat was 15 weeks old at the time of experiments. The control had the same age, but was bigger with a corresponding differences in organ weights (cf. Table 1) The animals were anesthetized
Table 1. Organ copper contents and weights.

\begin{tabular}{|c|c|c|c|c|}
\hline \multirow[t]{2}{*}{ Organ } & \multicolumn{2}{|l|}{ Control } & \multicolumn{2}{|l|}{ LEC } \\
\hline & $\begin{array}{l}\text { Weight } \\
{[\mathrm{g}]}\end{array}$ & $\begin{array}{l}\text { Copper } \\
{[\mu \mathrm{g}]^{\mathrm{a}}}\end{array}$ & $\begin{array}{l}\text { Weight } \\
{[\mathrm{g}]}\end{array}$ & $\begin{array}{l}\text { Copper } \\
{[\mu \mathrm{g}]^{\mathrm{a}}}\end{array}$ \\
\hline Body & 459 & $1 \times 10^{4}$ & 148 & $1 \times 10^{4}$ \\
\hline Liver & 13.9 & 27.7 & 4.71 & 59.4 \\
\hline Brain & 2.02 & 0.05 & 1.56 & 0.15 \\
\hline Spleen & 0.8 & 0.17 & 0.25 & 1.43 \\
\hline
\end{tabular}

${ }^{\mathrm{a}}$ Copper supplied to the animal.

and a bolus of $10 \mu \mathrm{g}$ of radioactive copper was administered as described under Material and methods. This was followed immediately by PET scans with $15 \mathrm{~min}$ time windows $(0-15,15-30$, $30-45,45-60,60-75,75-90,90-105,105-120$, $120-135,135-150,150-165,165-180 \mathrm{~min})$. After $180 \mathrm{~min}$, the animals were sacrificed by exsanguination and the spleen, the brain and the liver were harvested for $\beta$-counting. The liver was in addition examined by histology. The liver of the LEC rat had no signs of acute hepatitis with sub-massive necrosis, which can occur at this age (Terada \& Sugiyama 1999). No major fibrosis could be observed in either liver (data not shown).

PET data were acquired for 180 min and reconstructed in 15 min time frames. Two-dimensionally reconstructed pictures of the PET scans of the time frames from 0 to $15 \mathrm{~min}$ and from 165 to $180 \mathrm{~min}$ after copper administration are shown for control

\section{Control}

$15 \min$

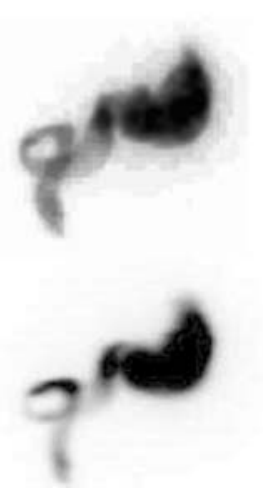

\section{LEC}

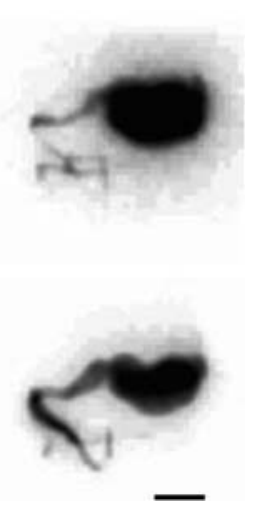

Figure 1. Reconstructed pictures of whole body PET. The three-dimensional PET scans were reconstructed to twodimensional images. Shown are the time frames from 0 to 15 min and from 165-180 min after copper administration for a control rat and an LEC rat. The bar corresponds to $1 \mathrm{~cm}$ and the resolution is $0.5 \mathrm{~mm}$. Movies of these PET scans can be found at www.ikp.unibe.ch/pet. 
and LEC rats in Figure 1. The shapes of the signals demarcate the silhouette of the stomach and the upper part of the intestine. The scans confirm on one hand the correct application of the radioactive copper and on the other hand show transport of copper out of the stomach into the intestine during the observation period. Movies of PET scans taken at the beginning and the end of the experiments are available on the Internet at http://www.ikp.unibe.ch/pet/.

The fraction of ${ }^{64} \mathrm{Cu}$ which was systemically absorbed could not be detected by the PET instrument due to the large background signal of the copper remaining in stomach and intestine. Radiocopper in bile, collected during the experiment, and in tissue was measured post mortem by $\beta$-counting (Table 1, Figure 2). Compared to the control, the LEC rat accumulated approximately twice as much copper in the liver, three times as much in the brain and eight times as much in the spleen. Since the organs of the LEC rat were smaller than in the control animal, the relative copper accumulation was even higher. In both animals, the highest amount of the systemically distributed copper was found in the liver.

In the control rat, copper excretion by the bile could be measured $15 \mathrm{~min}$ after the application of copper into the stomach. After an hour, a plateau phase was reached, with an intriguing sinusoidal fluctuation about the plateau value (Figure 2). As expected, in the LEC rat there was no measurable copper excretion, since the copper secreting ATPase, ATP7B, is defective in these animals.

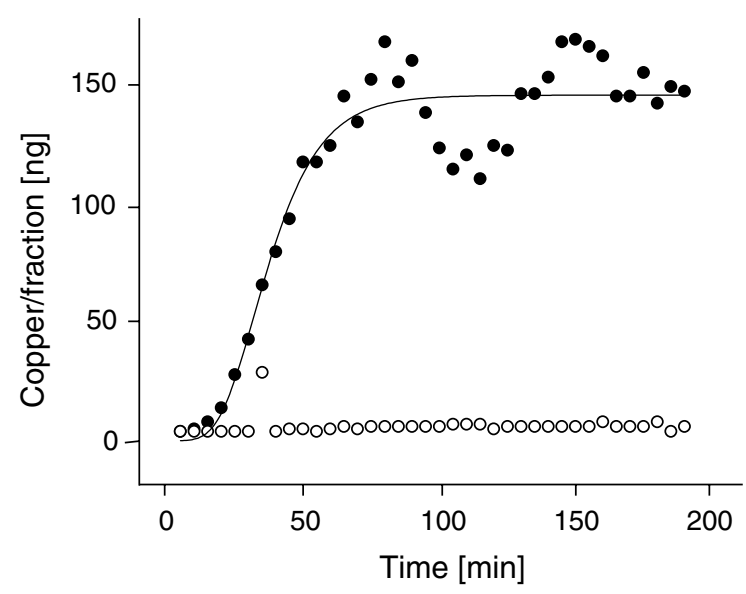

Figure 2. Copper excretion in bile. Fractions of $5 \mathrm{~min}$ were collected and the ${ }^{64} \mathrm{Cu}$ content was measured in control $(\mathbf{O})$ and LEC (O) rats.

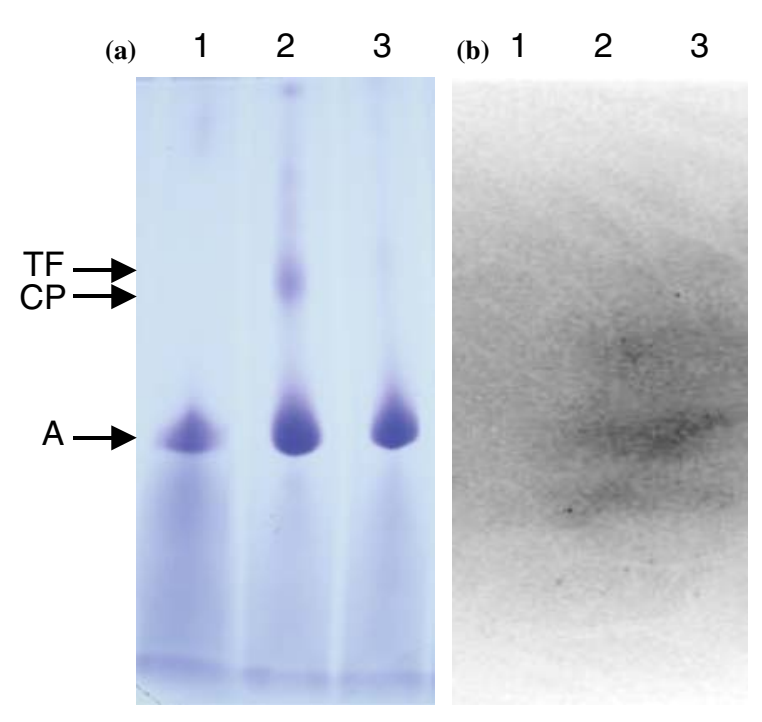

Figure 3. Native gel electrophoresis of serum proteins. Whole serum was separated on native gels, followed by staining with Coomassie blue (a) and autoradiography (b). Lane 1, $0.5 \mu \mathrm{g}$ of bovine serum albumin; lane 2, $0.5 \mu \mathrm{l}$ of serum from control rat, lane 3, $0.5 \mu \mathrm{l}$ serum of LEC rat. Serum samples were taken $3 \mathrm{~h}$ after injection of ${ }^{64} \mathrm{Cu}$. The arrows indicate the migration positions of ceruloplasmin (CP), transferrin (TF), and albumin (A). Further details are described under Methods.

To identify serum proteins which would primarily become copper loaded, non-denaturing, native blue gel electrophoresis of the serum was performed (Schagger \& von Jagow 1991). In this gel electrophoretic method, the proteins are not denatured and should thus retain bound copper. Figure 3 shows that the major copper binding protein was albumin. The autoradiography of Figure 3 suggests that other proteins of lower and higher molecular weight than albumin also bound copper, but their identity is not clear.

\section{Discussion}

Little is known about the intestinal absorption of copper. Bronner et al. examined the absorption of ${ }^{64} \mathrm{Cu}$ in the mouse duodenum by counting the radioactivity of the intestine at certain time points (up to $180 \mathrm{~min}$ ) (Bronner \& Yost 1985). They showed that within $60-120 \mathrm{~min}$ between 85 and $90 \%$ of the total copper was absorbed. Unfortuately, absorption in the stomach was not evaluated. Studies of the $60 \mathrm{~s}$ showed that the small intestine as well as the stomach show a mucosal absorption of copper (van Campen \& Mitchell 
1965; Marceau et al. 1970). However, mucosal uptake is not equivalent to systemic uptake. How much of intestinally absorbed copper actually reaches the circulation has not been sufficiently investigated so far.

We here investigated the possibility of using PET to measure copper fluxes in the whole animal. A major limitation to the technique proofed to be the extent of the dynamic range: weak signals of systemically absorbed copper could not be processed in the presence of the much stronger signal of the applied copper dose. Nevertheless, some insight could be gained. Our data show that a copper challenge resulted in trapping of copper in stomach and intestine. This was not affected by the different total body copper levels in the control and the LEC rat. Whether this trapped copper eventually enters the systemic copper pool is not clear. With the high turn over of mucosal and intestinal cells, trapped copper could get excreted by the natural cell sloughing. This could be a mechanism of protection from copper toxicity under acute conditions. In fact, the mechanism of copper secretion via the loss of intestinal cells is taken advantage of in one type of therapy for Wilson disease patients: orally administered zinc induces the synthesis of the heavy-metal binding protein metallothionein in enterocytes (Brewer 1995; Brewer et al. 1998). This pool of metallothionein in turn traps copper, thus lowering the system copper load in these patients. The copper trapped by the enterocytes leaves the organism via the stool by the normal sloughing off of cells.

As determined by post-mortem $\beta$-counting, a small fraction of copper was further distributed in the body. In the LEC rat, copper accumulation in the organs analyzed was several fold greater than in the control (Table 1). There was much more copper in the liver than in the spleen, which is one of the bloodiest organs. Hence, the copper was in the parenchymal cells and did not merely represent the amount of blood in the organ. Biliary copper excretion started 15 min after the administration of copper and plateaued at $1 \mathrm{~h}$ in the control rat. A similar onset of biliary excretion has been observed for the clearing of intravenously injected copper (Harada et al. 1993).

In the LEC rat, biliary secretion remained at background level, corroborating the key function of ATP7B in copper excretion into the bile.
However, a major contribution to the prevention of systemic over-absorption of excess copper seems to be accomplished by trapping of copper in the stomach and the intestine. Even if this trapped copper gets slowly absorbed over days, this 'storage' protects the organism from toxic serum levels that could not be managed by ATP7B. Further studies over longer observation periods would be needed to clarify the fate of the trapped copper. This is, however, not easily feasible with PET scanning as the animals have to be anesthetized during the observation period.

Taken together, our data suggest that copper trapping in the stomach and intestine may be an important mechanism to prevent toxic copper accumulation under conditions of excess copper intake. Assessing whole body copper flux by PET is limited by the dynamic range of current instrumentation, but is potentially useful in combination with other measurements.

\section{Acknowledgements}

We are grateful to August Schubiger for giving us access to the PET facility of the Paul Scherrer Institute and for his logistic support. We thank Hans Sägesser and Claudia Keller for technical assistance and Ilse Novak for her valuable support and suggestions on the experimental set-up. Part of this work was supported by Grant 31-68075.02 from the Swiss National Foundation and by the International Copper Association.

\section{References}

Andrews NC. 2002 Metal transporters and disease. Curr. Opin. Chem. Biol. 6, 181-186.

Brewer GJ. 1995 Practical recommendations and new therapies for Wilson's disease. Drugs 50, 240-249.

Brewer GJ, Dick RD, Johnson VD, Brunberg JA, Kluin KJ, Fink JK. 1998 Treatment of Wilson's disease with zinc: XV long-term follow-up studies. J. Lab Clin. Med. 132, 264-278.

Bronner F, Yost JH. 1985 Saturable and nonsaturable copper and calcium transport in mouse duodenum. Am. J. Physiol. 249, G108-G112.

Ferenci P, Caca K, Loudianos G, Mieli-Vergani G, Tanner S, Sternlieb I, Schilsky M, Cox D, Berr F. 2003 Diagnosis and phenotypic classification of Wilson disease. Liver 23, 139-142.

Forbes JR, Cox DW. 1998 Functional characterization of missense mutations in ATP7B: Wilson disease mutation or normal variant? Am. J. Hum. Genet. 63, 1663-1674. 
Harada M, Sakisaka S, Yoshitake M, Shakadoh S, Gondoh K, Sata M, Tanikawa K. 1993 Biliary copper excretion in acutely and chronically copper-loaded rats. Hepatology 17, 111-117.

Luk E, Jensen LT, Culotta VC. 2003 The many highways for intracellular trafficking of metals. J. Biol. Inorg. Chem. 8, 803-809.

Lutsenko S, Kaplan JH. 1995 Organization of P-type ATPases: Significance of structural diversity. Biochemistry 34, 1560715613.

Lutsenko S, Tsivkovskii R, Walker JM. 2003 Functional properties of the human copper-transporting ATPase ATP7B (the Wilson's disease protein) and regulation by metallochaperone Atox1. Ann. N. Y. Acad. Sci. 986, 204 211.

Marceau N, Aspin N, Sass-Kortsak A. 1970 Absorption of copper 64 from gastrointestinal tract of the rat. Am. J. Physiol. 218, 377-383.

Mercer JF, Barnes N, Stevenson J, Strausak D, Llanos RM. 2003 Copper-induced trafficking of the Cu-ATPases: a key mechanism for copper homeostasis. Biometals 16, 175-184.

Muratsubaki H, Satake K, Yamamoto Y, Enomoto K. 2002 Detection of serum proteins by native polyacrylamide gel electrophoresis using Blue Sepharose CL-6B-containing stacking gels. Anal. Biochem. 307, 337-340.

Petrukhin K, Fischer SG, Pirastu M, Tanzi RE, Chernov I, Devoto M, Brzustowicz LM, Cayanis E, Vitale E, Russo JJ. 1993 Mapping, cloning and genetic characterization of the region containing the Wilson disease gene. Nat Genet. 5, 338-343.

Prohaska JR, Gybina AA. 2004 Intracellular copper transport in mammals. J. Nutr. 134, 1003-1006.

Reader AJ, Erlandsson K, Flower MA, Ott RJ. 1998 Fast accurate iterative reconstruction for low-statistics positron volume imaging. Phys. Med. Biol. 43, 835-846.
Schagger H, von Jagow G. 1991 Blue native electrophoresis for isolation of membrane protein complexes in enzymatically active form. Anal. Biochem. 199, 223-231.

Schwarzbach R, Zimmermann K, Bläuenstein P, Smith A, Schubiger PA. 1995 Development of a simple and selective separation of ${ }^{67} \mathrm{Cu}$ from irradiated zinc for use in antibody labelling: a comparison of methods. Appl. Radiat. Isot. 46, 329-336.

Shah AB, Chernov I, Zhang HT, Ross BM, Das K, Lutsenko S, Parano E, Pavone L, Evgrafov O, Ivanova-Smolenskaya IA, Anneren G, Westermark K, Urrutia FH, Penchaszadeh GK, Sternlieb I, Scheinberg IH, Gilliam TC, Petrukhin K. 1997 Identification and analysis of mutations in the Wilson disease gene (ATP7B): population frequencies, genotypephenotype correlation, and functional analyses. Am. J. Hum. Genet. 61, 317-328.

Solioz M, Vulpe C. 1996 CPx-type ATPases: a class of P-type ATPases that pump heavy metals. Trends Biochem. Sci. 21, 237-241.

Tanzi RE, Petrukhin K, Chernov I, Pellequer JL, Wasco W, Ross B, Romano DM, Parano E, Pavone L, Brzustowicz LM. 1993 The Wilson disease gene is a copper transporting ATPase with homology to the Menkes disease gene. Nature Genet. 5, 344-350.

Terada K, Sugiyama T. 1999 The Long-Evans Cinnamon rat: an animal model for Wilson's disease. Pediatr. Int. 41, 414 418.

Thiele DJ. 2003 Integrating trace element metabolism from the cell to the whole organism. J. Nutr. 133, 1579S-1580S.

van Campen DR, Mitchell AE. 1965 Absorption of Cu-64, Zn65, Mo-99, and Fe-59 from ligated segments of the rat gastrintestinal tract. J. Nutr. 120-124.

Wu J, Forbes JR, Chen HS, Cox DW. 1994 The LEC rat has a deletion in the copper transporting ATPase gene homologous to the Wilson disease gene. Nature Genet. 7, 541-545. 